\title{
Utilização de cama sobreposta de suínos e sobressemeadura de leguminosas para aumento da produção e qualidade de pastagem natural ${ }^{1}$
}

\section{Paulo Hentz ${ }^{2}$, Simone Meredith Scheffer-Basso ${ }^{3,4}$, Pedro Alexandre Varella Escosteguy ${ }^{3}$, Roberto Serena Fontaneli ${ }^{3}$}

\footnotetext{
1 Trabalho financiado pelo CNPq.

2 Escola Agrotécnica Federal de Concórdia, SC.

3 Universidade de Passo Fundo.

${ }^{4}$ Bolsista CNPq.
}

RESUMO - Este trabalho foi conduzido com o objetivo de verificar o efeito da fertilização com dois tipos de camas sobrepostas de suínos (CSS), à base de casca de arroz (CA) e maravalha (MA), sobre a produção de uma pastagem natural, com predomínio de Axonopus sp. e Paspalum sp., sobressemeada com leguminosas (cornichão e trevo-branco). As camas sobrepostas foram aplicadas em quantidades equivalentes a 180, 360, 540 e $720 \mathrm{~kg} / \mathrm{ha}$ de $\mathrm{P}_{2} \mathrm{O}_{5}$, constituindo quatro níveis de cama de casca de arroz (30, 60, 90 ou 120 t/ha) e quatro níveis de cama de maravalha (20,6; 41,2; 62,2 ou 82,8 t/ha). Foram incluídos dois tratamentos-testemunha: $180 \mathrm{~kg} /$ ha de superfosfato triplo (SFT) e ausência de adubação (AA). A sobressemeadura das leguminosas foi realizada em maio de 2004 e, a partir de agosto de 2004, foram realizados nove cortes da pastagem, a cada seis semanas. As maiores produções de matéria seca (MS) anuais (setembro/2004 a agosto/2005) com as aplicações de cama de casca de arroz foram obtidas nos níveis 30 e 60 t/ha e, com cama de maravalha, nos níveis 62,2 e 82,8 t/ha, que resultaram em produções de MS de 8.083 e $8.276 \mathrm{~kg} / \mathrm{ha}$, superiores às obtidas com superfosfato triplo (4.091 kg MS/ha) e sem adubação (3.071 MS kg/ha). A produção de MS de trevo-branco aumentou linearmente no outono e no inverno, de acordo com os níveis de adubação com cama de maravalha, mas não variaram com a adubação com cama de casca de arroz. O efeito fertilizante varia entre os tipos de cama sobreposta, que podem influenciar a composição botânica de pastagens mistas de leguminosas-gramíneas.

Palavras-chave: esterco, Lotus corniculatus, Trifolium repens

\section{Swine deep bedding amendment and legume sod-seeding to increase production and quality of natural pasture}

\begin{abstract}
This work aimed to evaluate the effect of two swine deep beddings (SDB): rice husk (CA) and sawdust coarse (MA) on the production of natural pasture. The predominant species in this pasture were Axonopus sp. and Paspalum sp. that was sod-seeded with the forage legumes birdsfoot trefoil and white clover. The SDBs were applied in amounts equivalent to $180,360,540$, and $720 \mathrm{~kg} /$ ha of $\mathrm{P}_{2} \mathrm{O}_{5}$. In order to achieve the target $\mathrm{P}$ application, different levels of CA (30, 60, 90, and $120 \mathrm{t} / \mathrm{ha}$ ) and MA (20.6; 41.2; 62.2; and $82.8 \mathrm{t} / \mathrm{ha}$ ) were applied. Two control treatments were used: mineral fertilization (180 kg/ha of triple superphosphate, TSP) and no fertilization (AA). The legumes were sod-seeded in May/2004. After August/2004, the plants were cut every six weeks and nine cuts were performed. The highest annual (September/2004 to August/2005) dry matter (DM) production was obtained with 30 and 60 t/ha of CA or 62.2 and 82.8 t/ha of MA, with DM productivity ranging from 8,083 to $8,276 \mathrm{~kg}$ DM/ha. This productivity was greater than the one obtained with both TSP (4,091 kg DM/ha) and AA (3,071 kg DM/ha). The white-clover DM production increased linearly in the fall and in the winter seasons, as a function of MA and did not change with the CA rates. The results indicated that the CSS type (CA or MA) affects the fertilizing effect of these manures, influencing the production and the botanical composition of the pastures, specially the proportion of grasses and legumes.
\end{abstract}

Key Words: Lotus corniculatus, manure, Trifolium repens

\section{Introdução}

A produção anual das pastagens naturais no Sul do Brasil oscila entre 3 e 5 t/ha de matéria seca (MS) e carac- teriza-se pela predominância de gramíneas estivais durante a primavera/verão, com muito pouca produção no inverno e com declínio acentuado na qualidade no outono (Ritter \& Sorrenson, 1985). 
Essa limitação pode ser reduzida com a introdução de leguminosas hibernais e adubação (Macedo et al., 1985; Fontaneli et al., 1991; Rizo et al., 2004). O trevo-branco (Trifolium repens L.) é uma das principais opções para essa prática, pois seu hábito de crescimento estolonífero adapta-se ao sistema de pastejo predominante na região, que é o de lotação contínua. No entanto, a acidez e a baixa fertilidade natural dos solos dessa região limitam o seu crescimento (Bandinelli, 2005). O cornichão (Lotus corniculatus L.) é mais tolerante a essa situação, mas tem menor capacidade competitiva.

Diversos trabalhos têm confirmado a importância da adubação fosfatada para a introdução de leguminosas temperadas, particularmente exigentes em fósforo e pouco tolerantes a teores elevados de alumínio tóxico (Prestes \& Jacques, 2002). Uma das possibilidades para a adubação de pastagens é utilizar cama sobreposta de suínos, pois a Região Sul concentra grande número de propriedades com atividade na suinocultura intensiva. No sistema de cama sobreposta de suínos, os dejetos líquidos são misturados a um substrato sólido (maravalha, casca de arroz, etc.) dentro das edificações e são submetidos a um processo de compostagem e estabilização in situ, com a presença dos animais.

Os adubos orgânicos apresentam concentrações e taxas de liberação de nutrientes no solo muito variáveis, e para CSS ainda não se dispõe dos índices de disponibilidade (ID) dos principais nutrientes, como o nitrogênio, o fósforo e o potássio. Esses índices são conhecidos para as camas de frango e correspondem a 0,5, 0,8 e 1,0 para o N, P e K, respectivamente, no primeiro cultivo (SBCS, 2004). Como o sistema de criação em cama sobreposta de suínos é recente, pouco se conhece, também, sobre as quantidades a serem utilizadas nas culturas (Liebman et al., 2004; Menalled et al., 2005). No Rio Grande do Sul, Arns (2004) obteve maior produção de aveia-branca (Avena sativa L.) com 30 t/ha de cama sobreposta de suínos.

Este trabalho foi conduzido com o objetivo de avaliar o impacto de dois tipos de cama sobreposta de suínos em uma pastagem natural sobressemeada com leguminosas, pela avaliação da composição botânica, produção e composição química da matéria seca.

\section{Material e Métodos}

O trabalho foi conduzido entre novembro de 2003 e agosto de 2005 em área de pastagem natural cercada com tela, com predomínio de Axonopus sp. e Paspalum sp., em Concórdia, Santa Catarina, cujo clima é subtropical úmido
(Cfa) (Figura 1). Foram registradas oito geadas entre maio e agosto de 2004 e cinco geadas entre maio e julho de 2005.

O solo da área é um Nitossolo Vermelho eutroférrico chernossólico. Considerando a acidez potencial $(\mathrm{pH}=4,8$; $\mathrm{Al}=1,5 \mathrm{cmol}_{\mathrm{C}} / \mathrm{dm}^{3}$ ), em novembro de 2003, seis meses antes da introdução das leguminosas, foram aplicadas $4 \mathrm{t}$ de calcário/ha, quantidade equivalente a um terço da recomendada para elevar o pH a 6,5 (SBCS, 2004) caso o corretivo fosse incorporado (Prestes \& Jacques, 2002). Em abril de 2004, foram realizadas novas amostragens em todas as parcelas para análise de seus atributos físico-químicos (Tabela 1).

O experimento constou de dez tratamentos, alocados em delineamento de blocos casualizados, com três repetições: a) $180 \mathrm{~kg} /$ ha de $\mathrm{P}_{2} \mathrm{O}_{5}$ na forma de superfosfato triplo (SFT); b) ausência de adubação (AA); c) adubação com cama sobreposta de suínos (CSS) à base de maravalha (MA) e casca de arroz (CA), em quatro doses cada uma. As camas foram aplicadas em quantidades equivalentes a 180, 360,

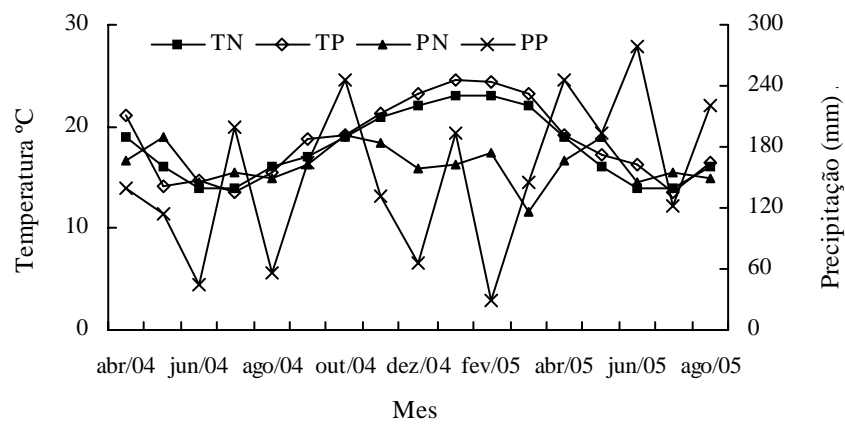

Figura 1 - Temperatura média $(T P=$ período; $T N=$ normais $)$ e precipitação pluvial mensal $(\mathrm{PP}=$ período; $\mathrm{PN}=$ normais $)$ durante o período experimental e as normais regionais. Fonte: Embrapa Suínos e Aves, Concórdia, SC.

Tabela 1 - Atributos físico-químicos do solo após a calagem e antes da adubação

\begin{tabular}{lrrr}
\hline Atributos do solo & \multicolumn{3}{c}{ Camada } \\
\cline { 2 - 4 } & $0-5 \mathrm{~cm}$ & $5-10 \mathrm{~cm}$ & $10-20 \mathrm{~cm}$ \\
\hline Argila $(\%)$ & 38,0 & 38,0 & 46,0 \\
pH $\left(\mathrm{H}_{2} \mathrm{O}\right)$ & 5,5 & 5,3 & 5,1 \\
pH (SMP) & 5,0 & 4,8 & 4,5 \\
$\mathrm{~K}$ extraível $\left(\mathrm{mg} / \mathrm{dm}^{3}\right)$ & 167,0 & 118,0 & 98,0 \\
P extraível $\left(\mathrm{mg} / \mathrm{dm}^{3}\right)$ & 2,0 & 2,0 & 2,0 \\
Matéria orgânica $(\%)$ & 3,4 & 2,9 & 2,3 \\
Al trocável $\left(\mathrm{cmol}_{\mathrm{c}} / \mathrm{dm}^{3}\right)$ & 3,1 & 3,5 & 4,6 \\
Ca trocável $\left(\mathrm{cmol}_{\mathrm{c}} / \mathrm{dm}^{3}\right)$ & 3,8 & 3,0 & 2,3 \\
Mg trocável $\left(\mathrm{cmol}_{\mathrm{c}} / \mathrm{dm}^{3}\right)$ & 2,3 & 1,6 & 1,3 \\
$\mathrm{H}+$ Al $\left(\mathrm{cmol}_{\mathrm{c}} / \mathrm{dm}^{3}\right)$ & 13,7 & 17,3 & 24,4 \\
$\mathrm{CTC}(\mathrm{pH} 7,0)\left(\mathrm{cmol}_{\mathrm{c}} / \mathrm{dm}^{3}\right)$ & 20,3 & 22,2 & 26,2 \\
\hline
\end{tabular}


540 e $720 \mathrm{~kg} /$ ha de $\mathrm{P}_{2} \mathrm{O}_{5}$. Essas doses foram estabelecidas assumindo-se que o ID de fósforo para o primeiro cultivo fosse de 100, 50, 33,33 e 25\%, respectivamente. Em razão das diferentes concentrações de $\mathrm{P}_{2} \mathrm{O}_{5}$ das camas sobrepostas, as quantidades aplicadas corresponderam a: 30, 60, 90 e $120 \mathrm{t} / \mathrm{ha}$ de cama de casca de arroz e 20,6; 41,2; 62,2 e 82,8 t/ha de cama de maravalha. A quantidade de fósforo aplicada com o SFT foi escolhida de acordo com as leguminosas sobressemeadas (SBCS, 2004). Como a concentração de potássio e dos demais nutrientes estava dentro dos limites aceitáveis para essas espécies, não foi necessária sua aplicação. As cama sobrepostas foram oriundas de três lotes de criação de suínos no ano de 2003 (Tabela 2).

As unidades experimentais foram formadas por parcelas de $4 \mathrm{~m} \times 8 \mathrm{~m}\left(32 \mathrm{~m}^{2}\right)$ distantes $1 \mathrm{~m}$ entre si nos blocos e $1 \mathrm{~m}$ entre blocos. A distribuição dos adubos foi realizada manualmente e sobre a superfície da pastagem recémroçada em 21/4/2004. Na semana seguinte (3/5/2004), após a ocorrência de chuvas, foi feita a sobressemeadura das leguminosas em superfície e a lanço, em todas as parcelas, nas seguintes densidades: $8 \mathrm{~kg} / \mathrm{ha}$ de Lotus corniculatus L. cv. São Gabriel (65\% de germinação) e 2 kg/ha de Trifolium repens cv. Yi (80\% de germinação). As sementes foram inoculadas com rizóbio específico e peletizadas antes da semeadura. A pastagem foi manejada mediante cortes

Tabela 2 - Atributos físico-químicos das camas sobrepostas de suínos aplicadas sobre uma pastagem natural sobressemeada com leguminosas forrageiras

\begin{tabular}{|c|c|c|}
\hline \multirow[t]{2}{*}{ Atributo físico-químico } & \multicolumn{2}{|c|}{ Tipo de cama sobreposta de suíno } \\
\hline & Casca de arroz (\%) & Maravalha (\%) \\
\hline \multicolumn{3}{|c|}{ Tamanho das partículas (mm) } \\
\hline$>6,0$ & 0,00 & 4,18 \\
\hline $6,0-4,6$ & 9,80 & 3,40 \\
\hline $4,6-2,0$ & 9,80 & 15,50 \\
\hline$<2,0$ & 90,20 & 76,92 \\
\hline $\mathrm{N}$ total & 0,61 & 0,80 \\
\hline $\mathrm{N}$ mineral & 0,16 & 0,35 \\
\hline $\mathrm{P}_{2} \mathrm{O}_{5}$ total & 0,60 & 0,87 \\
\hline $\mathrm{K}_{2} \mathrm{O}$ total & 0,58 & 1,09 \\
\hline Umidade $\left(65^{\circ} \mathrm{C}\right)$ & 41,87 & 42,90 \\
\hline Matéria orgânica & 34,76 & 45,84 \\
\hline $\mathrm{pH}$ em $\mathrm{CaCl}_{2}$ 0,1M (1:5) & 8,30 & 8,80 \\
\hline Са & 0,72 & 0,41 \\
\hline $\mathrm{Mg}$ & 0,21 & 0,08 \\
\hline $\mathrm{Mn}$ & 0,02 & 0,01 \\
\hline $\mathrm{Cu}$ & 0,01 & 0,01 \\
\hline $\mathrm{Zn}$ & 0,01 & 0,01 \\
\hline $\mathrm{Fe}$ & 0,31 & 0,09 \\
\hline$S$ & 0,08 & 0,06 \\
\hline Relação C/N & 31,65 & 31,83 \\
\hline $\mathrm{pH}$ em $\mathrm{CaCl}_{2} 0,1 \mathrm{M}(1: 5)$ & 8,30 & 8,80 \\
\hline
\end{tabular}

periódicos, feitos a cada seis semanas (Magnanti et al., 2005; Prestes \& Jacques, 2002), entre 17/9/2004 e 26/8/2005, a fim de se obterem duas informações por estação. Estes cortes foram realizados com auxílio de uma tesoura de aparar gramado, deixando-se um resíduo de cerca de $7 \mathrm{~cm}$. A produção de MS foi estimada mediante a pesagem do material vegetal cortado em uma área de $1 \mathrm{~m}^{2}$, localizada no centro das parcelas, da qual foi retirada uma subamostra para secagem em estufa de ventilação a $60^{\circ} \mathrm{C}$, para avaliação do teor de MS, PB, FDA e FDN. Imediatamente antes dos cortes, foi avaliada a altura da pastagem com auxílio de uma lâmina plástica colocada sobre o dossel.

A composição botânica foi realizada pelo método de separação e peso dos principais componentes (gramíneas, trevo-branco, cornichão e material morto) presentes em uma área demarcada aleatoriamente com um quadrado metálico de 0,50 m x 0,50 m (Whalley \& Hardy, 2000; Prestes \& Jacques, 2002; Magnanti et al., 2005), dentro do qual foi cortado e recolhido todo o material vegetal presente acima de $7 \mathrm{~cm}$. Em seguida, a área foi roçada e limpa com auxílio de ancinhos. A estimativa da ocorrência e abundância de nódulos de rizóbio foi feita por ocasião do primeiro corte, mediante a retirada de uma planta de cada espécie na bordadura de cada parcela.

A análise da variância foi realizada separadamente para os dados referentes ao período de estabelecimento das leguminosas, às estações do ano e ao ano e, para a composição química, foram considerados todos os dados obtidos dos nove cortes realizados. Para a análise adubação $\times$ estação utilizou-se o modelo de parcela subdividida no tempo (parcela principal = adubação; subparcela = estação). As médias foram comparadas pelo teste de Tukey a 5\% de significância. Complementarmente, foi executada a análise de regressão dentro de cada tipo de cama sobreposta considerando as quantidades utilizadas destes adubos.

\section{Resultados e Discussão}

Entre as leguminosas sobressemeadas, cujo estabelecimento foi avaliado aos 134 dias após a sobressemeadura, por ocasião do primeiro corte, o trevo-branco destacou-se em relação ao cornichão e participou, na média, em $60 \%$ da MS total da pastagem (Tabela 3). Esta espécie foi especialmente favorecida pela adubação com cama de maravalha no nível de 62,2 t/ha, se comparada às testemunhas, nas quais se verificou $74 \%$ da MS produzida. Por outro lado, sem adubação, a participação desta espécie foi muito pequena (26\%), evidenciando a importância desse fator de manejo para o estabelecimento de leguminosas em pastagens 
Tabela 3 - Produção de matéria seca de cornichão e trevo-branco de uma pastagem natural adubada com superfosfato triplo ou cama sobreposta de suínos à base de casca de arroz ou de maravalha

\begin{tabular}{lccc}
\hline Adubação & Cornichão & $\begin{array}{c}\text { Trevo-branco } \\
\text { MS (kg/ha) }\end{array}$ & MS total \\
& & $33,2 \mathrm{~b}$ & $78,7 \mathrm{c}$ \\
Superfosfato triplo & $9,0 \mathrm{~ns}$ & $11,9 \mathrm{~b}$ & $57,5 \mathrm{c}$ \\
Sem adubação & 44,4 & $164,5 \mathrm{ab}$ & $375,6 \mathrm{bc}$ \\
Casca de arroz (30 t/ha) & 16,3 & $149,5 \mathrm{ab}$ & $301,6 \mathrm{c}$ \\
Casca de arroz (60 t/ha) & 63,4 & $326,9 \mathrm{ab}$ & $601,4 \mathrm{abc}$ \\
Casca de arroz (90 t/ha) & 1,2 & $45,2 \mathrm{ab}$ & $133,2 \mathrm{c}$ \\
Casca de arroz (120 t/ha) & 82,8 & $358,1 \mathrm{ab}$ & $705,2 \mathrm{abc}$ \\
Maravalha 20,6 t/ha & 57,8 & $309,2 \mathrm{ab}$ & $637,6 \mathrm{abc}$ \\
Maravalha 41,2 t/ha & 79,8 & $924,0 \mathrm{a}$ & $1.249,7 \mathrm{a}$ \\
Maravalha 62,2 t/ha & 101,5 & $795,4 \mathrm{ab}$ & $1.078,5 \mathrm{ab}$ \\
Maravalha 82,8 t/ha & 45,93 & 311,7 & 521,9 \\
Média & 99,3 & 90,8 & 47,3 \\
CV (\%) & & & 4 \\
\hline
\end{tabular}

Médias seguidas de mesma letra não diferem $(P>0,05)$ pelo teste Tukey.

naturais do Sul do Brasil, como indicado por Gatiboni et al. (2000).

As diferenças de produção de MS da pastagem foram, basicamente, decorrentes da resposta do trevo-branco. As observações visuais nas raízes das duas leguminosas evidenciaram excelente nodulação, indicando que o nitrogênio do adubo orgânico não inibiu a simbiose. Sabe-se que uma pequena oferta de $\mathrm{N}$-mineral do solo é necessária para trevos até a formação do nódulo e o início da fixação de N; portanto, o uso do fertilizante nitrogenado é essencial em solos com baixa fertilidade ou deficiência deste nutriente (Haystead \& Marriott, 1979).

É possível que o cornichão, cuja participação na MS da pastagem foi pequena (9\%), tenha sido semeado em baixa densidade, em comparação à realizada por Prestes \& Jacques (2002) (20 kg/ha) em estudo similar, além de sua menor capacidade de competição (Guretsky et al., 2004). Os elevados coeficientes de variação não permitiram detectar maiores diferenças entre as médias, apesar da tendência no aumento da produção desta espécie com as camas sobrepostas de suínos (Tabela 3). Este fato é comumente verificado em estudos deste tipo, pois dificilmente se obtém estabelecimento uniforme de espécies sobressemeadas e geralmente ocorrem muitas variações em uma pastagem natural, que é floristicamente diversificada, heterogênea e competitiva (Magnanti et al., 2005; Prestes \& Jacques, 2002).

Comparando-se as camas sobrepostas quanto à grandeza da variação na produção de MS da pastagem com a aplicação de até 62 t/ha de cama de maravalha e 90 t/ha da cama de casca de arroz, observa-se que os aumentos foram similares em comparação à dose imediatamente inferior. No entanto, com a maior dose aplicada, a redução com a aplicação de cama de casca de arroz (120 t/ha) foi de 77,8\% e de apenas 13,7\% com cama de maravalha (82,8 t/ha). Essa tendência também foi observada na produção das leguminosas. A grande quantidade de cama sobreposta à base de casca de $\operatorname{arroz}(120 \mathrm{t} / \mathrm{ha}$ ) formou uma espessa camada sobre a pastagem, recobrindo e sombreando totalmente as plantas, o que retardou a emergência das plântulas das leguminosas, estiolando as gramíneas presentes na área. Esse aspecto é relevante porque a resposta do trevo-branco à diminuição da intensidade de luz é a redução na formação de estolões a partir de gemas axilares (Beinhart et al., 1963).

Além disso, os trabalhos de Santos et al. (2002) e Tamak et al. (1994) indicam que outros aspectos podem ter interferido nesse efeito, como a adição, pelas camas sobrepostas de suínos, de substâncias aleloquímicas, que inibem a germinação de sementes. Menalled et al. (2005) verificaram que camas sobrepostas à base de palha de cereais inibiram a emergência de invasoras, especialmente daquelas com sementes pequenas, similares às do trevo-branco. Esse efeito pode estar relacionado a compostos fitotóxicos, incluindo ácidos graxos, fenóis e amônia, existentes em camas sobrepostas de suínos (Ligneau \& Watt, 1995).

A produção estacional variou entre os tipos e as quantidades de cama sobreposta em maior ou menor grau e, de modo geral, as camas sobrepostas de suínos foram, no mínimo, tão eficientes quanto o superfosfato triplo, indicando seu valor como fertilizante para aumento da produção de MS de pastagens naturais, estimulando o crescimento de gramíneas e viabilizando a introdução de leguminosas. Esse resultado está de acordo com os descritos por Lobato \& Barreto (1975), segundo os quais somente com calagem e a adubação de solos ácidos é possível dobrar ou triplicar a produção das pastagens naturais, como de fato foi observado neste trabalho.

A maior produção média estacional de MS foi obtida na primavera, superando em 75, 68 e 78\% às verificadas no 
Tabela 4 - Produção de matéria seca (MS) estacional e anual de uma pastagem natural sobressemeada com leguminosas adubada com superfosfato triplo ou cama sobreposta de suínos à base de casca de arroz ou de maravalha

\begin{tabular}{|c|c|c|c|c|c|}
\hline \multirow[t]{2}{*}{ Adubação } & Primavera & Verão & \multirow{2}{*}{$\begin{array}{c}\text { Outono } \\
\text { MS (kg/ha) }\end{array}$} & Inverno & \multirow[t]{2}{*}{ Anual } \\
\hline & & & & & \\
\hline Superfosfato triplo & 1.697abA & $1.073 \mathrm{nsAB}$ & $639 c B$ & 682bAB & $4.091 \mathrm{bc}$ \\
\hline Sem adubação & $858 b A$ & $59 \mathrm{~A}$ & $761 \mathrm{bcA}$ & 493bA & $3.071 \mathrm{c}$ \\
\hline Casca de arroz (30 t/ha) & $2.928 \mathrm{aA}$ & $1.884 \mathrm{AB}$ & 1.796abAB & $1.581 \mathrm{abB}$ & $8.188 a$ \\
\hline Casca de arroz (60 t/ha) & $2.888 \mathrm{aA}$ & $1.608 \mathrm{~B}$ & $1.902 \mathrm{aAB}$ & 1.685abB & $8.083 a$ \\
\hline Casca de arroz (90 t/ha) & $2.550 \mathrm{aA}$ & $1.339 \mathrm{~A}$ & $1.300 \mathrm{abcA}$ & $1.475 \mathrm{abA}$ & $6.664 \mathrm{ab}$ \\
\hline Casca de arroz (120 t/ha) & $2.148 \mathrm{abA}$ & $2.347 \mathrm{~A}$ & $1.474 \mathrm{abcA}$ & $1.445 \mathrm{abA}$ & $7.414 \mathrm{ab}$ \\
\hline Maravalha 20,6 t/ha & $3.105 \mathrm{aA}$ & $1.229 \mathrm{~B}$ & $1.321 \mathrm{abcB}$ & $1.060 \mathrm{abB}$ & $6.715 \mathrm{ab}$ \\
\hline Maravalha 41,2 t/ha & $2.798 \mathrm{aA}$ & $1.480 \mathrm{~A}$ & 1.718abA & $1.126 \mathrm{abA}$ & $7.121 \mathrm{ab}$ \\
\hline Maravalha 62,2 t/ha & $3.044 \mathrm{aA}$ & $1.298 B$ & $1.974 \mathrm{aAB}$ & 1.846abB & $8.162 \mathrm{a}$ \\
\hline Maravalha 82,8 t/ha & $2.785 \mathrm{aA}$ & $1.021 \mathrm{~B}$ & $1.907 \mathrm{aAB}$ & $2.563 \mathrm{aA}$ & $8.276 a$ \\
\hline Média CA & $2.628 \mathrm{~ns}$ & $1.794 \mathrm{a}$ & $1.628 \mathrm{~ns}$ & $1.546 \mathrm{~ns}$ & $7.587 \mathrm{~ns}$ \\
\hline Média MA & 2.933 & $1.257 \mathrm{~b}$ & 1.729 & 1.648 & 7.568 \\
\hline Média geral & $2.491 \mathrm{~A}$ & 1.394B & $1.479 \mathrm{~B}$ & 1.394B & \\
\hline CV (\%) & 19,3 & 38,8 & 24,4 & 44,9 & 15,3 \\
\hline
\end{tabular}

Médias seguidas de mesma letra, minúscula na coluna e maiúscula na linha, não diferem $(P>0,05)$ pelo teste Tukey.

verão, outono e inverno, respectivamente. Com a estiagem ocorrida no verão, a produção foi aquém do normal em comparação às obtidas no outono e inverno, o que não é comum na Região Sul do Brasil, onde ocorre sobra de pasto na estação quente. Entre os tratamentos, aqueles que proporcionaram melhor distribuição estacional, ou seja, os que variaram menos, foram os de cama sobreposta à base de casca de arroz (Tabela 4).

No Sul do Brasil, um fator importante é que, além de elevar a produção anual, as técnicas de manejo propiciem a melhoria na distribuição estacional, pois normalmente há excesso de MS no verão e severa deficiência no outonoinverno e no valor nutritivo. A adubação é imprescindível para reduzir esse problema, uma vez que viabiliza o estabelecimento, a produção e a persistência de leguminosas, além de melhorar o desempenho das gramíneas. Nesse sentido, com a cama de maravalha, obteve-se maior proporção relativa de MS na estação fria, em virtude do melhor desempenho do trevo-branco, e com cama de casca de arroz, houve maior equilíbrio entre os dois períodos (Figura 2). As proporções de gramíneas e leguminosas também indicam a necessidade e/ou possibilidade de um manejo diferencial em situações de um excesso de leguminosas, com risco de timpanismo. As áreas com grande participação de trevo-branco poderiam ser reservadas, por exemplo, como banco de proteína no outono-inverno.

Somente com cama sobreposta à base de maravalha houve efeito significativo do nível na produção de MS de trevo-branco, cuja resposta foi linear no outono e no inverno (Figura3), épocas em que houve a retomada do seu crescimento. Esta espécie mostrou excepcional recuperação, pois passou por uma séria estiagem no verão, que ocasionou sua senescência, mas retomou seu crescimento na estação fria, indicando boa persistência, especialmente com as duas maiores doses de cama sobreposta à base de maravalha (Figura 3).

Os estudos com cama sobreposta de suínos para uso como fertilizantes ainda são escassos e não há informações quanto ao efeito do substrato na ação destes compostos como fertilizante. É possível que a maior concentração de N, Ke MO da cama de maravalha (Tabela 2) em relação à cama
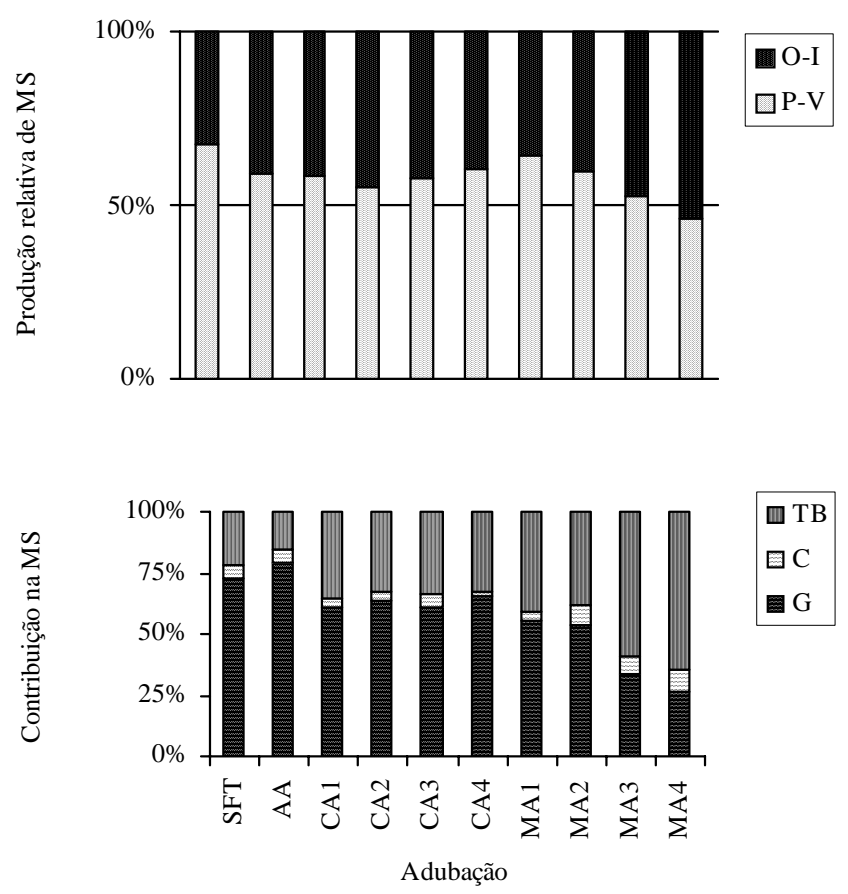

Figura 2 - Produção relativa de MS total na primavera-verão e no outono-inverno e contribuição estacional de gramíneas $(G)$, cornichão (C) e trevo-branco (TB) em uma pastagem natural sem adubação (AA) e adubada com superfosfato triplo (SFT) ou cama sobreposta de suínos à base de casca de arroz (CA) ou de maravalha (MA). 

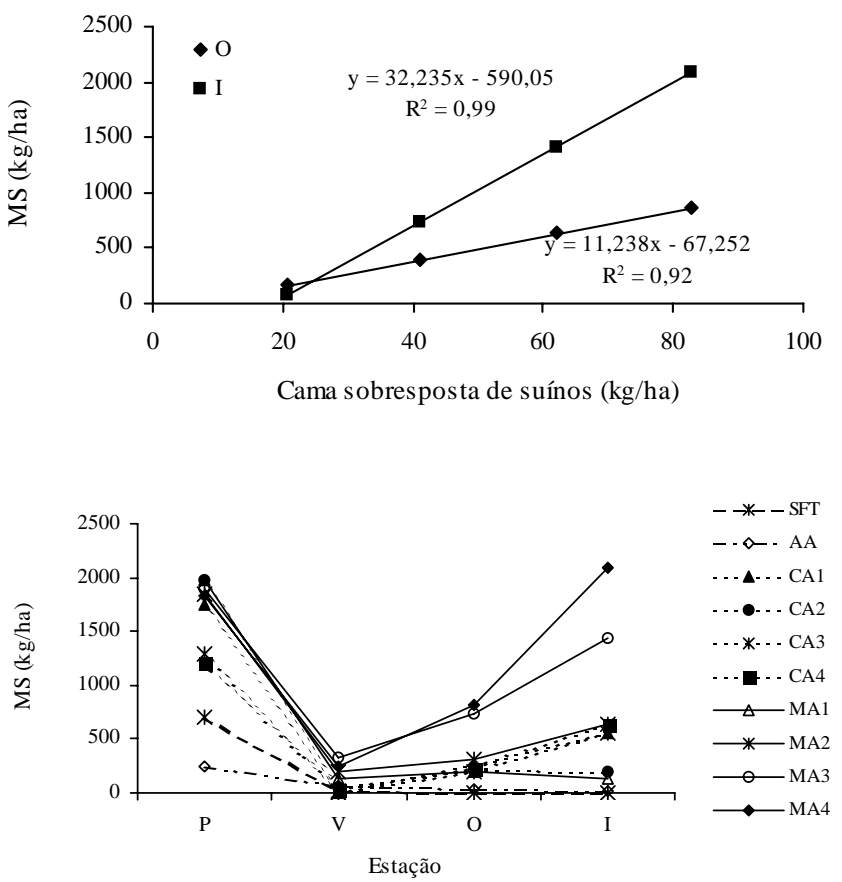

Figura 3 - Produção de matéria seca (MS) no outono (O) e inverno (I) do trevo-branco em pastagem adubada com cama sobreposta de suínos à base de maravalha. Médias estacionais obtidas sem adubação (AA) e com a adubação com superfosfato triplo (SFT) ou cama sobreposta de suínos à base de casca de arroz (CA) ou de maravalha (MA).

de casca de arroz tenha sido determinante no desempenho do trevo-branco. Outros fatores que podem ter influenciado na resposta do trevo-branco nos dois tipos de cama são de natureza física, pois os adubos orgânicos são condicionadores do solo (Alcarde et al., 1989; Liebman et al., 2004). Ao proporcionar um microambiente mais favorável quanto à umidade, há o favorecimento do crescimento das plantas, especialmente espécies estoloníferas, como o trevo-branco, que é sensível ao déficit hídrico (Low \& Piper, 1960).

Resende et al. (2005), ao compararem resíduos agroindustriais como substrato na produção de mudas de tomateiro (Lycopersicum esculentum L.), constataram que a maravalha propiciou melhores condições de germinação das sementes, em razão da maior capacidade de retenção de água em comparação à casca de arroz carbonizada. Liebman et al. (2004) verificaram respostas distintas de plantas invasoras (Abutilon sp., Amaranthus sp., Setaria spp.) à aplicação de cama sobreposta de suínos. Além disso, não se pode negligenciar um possível efeito dos tipos de cama sobreposta de suínos na eficiência da fixação biológica de nitrogênio.

No total anual, quatro tratamentos (30 e 60 t/ha de casca de arroz, 62,2 e 82,8 t/ha de maravalha) destacaram-se quanto ao aumento de MS obtido com o superfosfato triplo, com aumentos acima de 97\% (Tabela 4). Em geral, a resposta de pastagens ao fósforo é condicionada, além da correção da acidez do solo, à adição de doses adequadas de outros nutrientes e do aumento do teor de matéria orgânica (Souza et al., 2004). Assim, não se pode creditar a superioridade dos tratamentos com cama sobreposta de suínos somente às quantidades de fósforo, uma vez que há presença de outros nutrientes e de matéria orgânica nesses materiais. No entanto, como o solo utilizado no experimento tinha limitação somente de fósforo e alumínio (Tabela 1), a probabilidade de resposta das leguminosas sobressemeadas à adubação com outros nutrientes essenciais seria muito baixa ou nula (SBCS, 2004). Por isso, além de corrigir os níveis de fósforo e melhorar o excesso de alumínio, considerou-se que os efeitos das camas sobreposta de suínos sobre os demais nutrientes seriam secundários.

No entanto, o teor de alumínio do solo pouco diferiu entre as camas sobrepostas de suínos e superfosfato triplo (Tabela 5), o que indica que o efeito do fósforo adicionado às camas sobrepostas, ou que, principalmente, esse efeito foi relevante para diferenciar os tratamentos. A menor resposta da pastagem ao SFT em relação aos quatro melhores tratamentos pode estar relacionada às limitações do solo, que restringiram seu efeito. Embora o teor de Al do solo tratado com as maiores quantidades de cama sobreposta à base de casca de arroz $\left(0,1 \mathrm{a} 0,3 \mathrm{cmol}_{\mathrm{C}} / \mathrm{dm}^{3}\right)$ tenha sido menor que os obtidos nos solos tratados com as demais aplicações de cama sobreposta de suínos e com SFT ( 0,7 a $\left.1,1 \mathrm{cmol}_{c} / \mathrm{dm}^{3}\right)$, além de ser maior no solo testemunha $\left(1,5 \mathrm{cmol}_{c} / \mathrm{dm}^{3}\right)$ que nos solos com esses últimos tratamentos, as diferenças de MS observada entre os tratamentos (Tabela 4) não devem estar relacionadas ao efeito das camas sobre os teores de $\mathrm{Al}$ do solo, pois esse efeito não foi observado em todos os tratamentos.

Entretanto, o teor elevado desse metal no solo com superfosfato triplo pode ter limitado sua eficiência, pois o fósforo adicionado a esse tipo de adubo pode ser rapidamente solubilizado e, com isso, reagir com o alumínio, formando fosfato de alumínio, composto de baixa solubilidade. Essa limitação deve ter sido amenizada nos tratamentos com cama sobreposta de suínos, uma vez que o P é adicionado na forma de vários compostos orgânicos, que mineralizam e disponibilizam gradativamente esse nutriente às plantas.

Além disso, com a adubação com cama de casca de arroz nos níveis de 90 e 120 t/ha, houve decréscimo do alumínio trocável do solo em relação ao SFT e aos outros níveis de cama sobreposta. Esse efeito sugere que houve complexação desse mineral por compostos orgânicos, possivelmente adicionados com os maiores níveis de cama de casca de 
arroz. Além disso, os maiores teores de cálcio e manganês obtidos com 90 t/ha de cama de casca de arroz sugerem que o efeito positivo desses cátions sobre o desenvolvimento das raízes também pode ter contribuído para a maior eficiência desse tratamento.

Os efeitos das camas sobrepostas podem estar relacionados a outros fatores. A modificação da diversidade de fungos micorrízicos e patogênicos também pode afetar o crescimento das plantas adubadas com camas sobrepostas (Douds et al., 1997). Valdrighi al. (1996) relataram que este adubo é fonte de substâncias estimulantes ao crescimento vegetal, como ácido indol-acético, ácidos fúlvicos e húmicos, e que os benefícios dessas substâncias seriam decorrentes do aumento da permeabilidade da membrana celular, maior absorção de nutrientes e da melhoria nos processos de síntese de proteína, entre outros. Liebman et al. (2004) acrescentaram que os dejetos compostados podem alterar características físico-químicas do solo, como a umidade, o regime térmico e a atividade microbiana.

As alterações na composição botânica promoveram diferenças nos teores de PB, FDA e FDN, melhorando a qualidade da forragem onde houve maior participação do trevo-branco (Tabela 6), o que indica a importância desta prática como meio de melhorar qualitativamente o valor nutricional das pastagens (Quadros et al., 1987). O trevobranco é, notoriamente, uma leguminosa de excelente qualidade e que, em estádio vegetativo, apresenta concentrações de parede celular entre 35,0 a 42\% e fração lignocelulósica entre 21 e 23,0\% (NRC, 1988).

Apesar da viabilidade de se utilizar os dejetos de suínos nas pastagens, esta prática é complexa e ainda incipiente no Brasil, sendo necessários muitos estudos para possibilitar sua utilização segura e sustentável. Os resultados deste trabalho indicam que as camas sobrepostas de suínos

Tabela 5 - Atributos químicos do solo adubado com superfosfato triplo (SFT) ou cama sobreposta de suínos à base de casca de arroz ou de maravalha ao final do período experimental

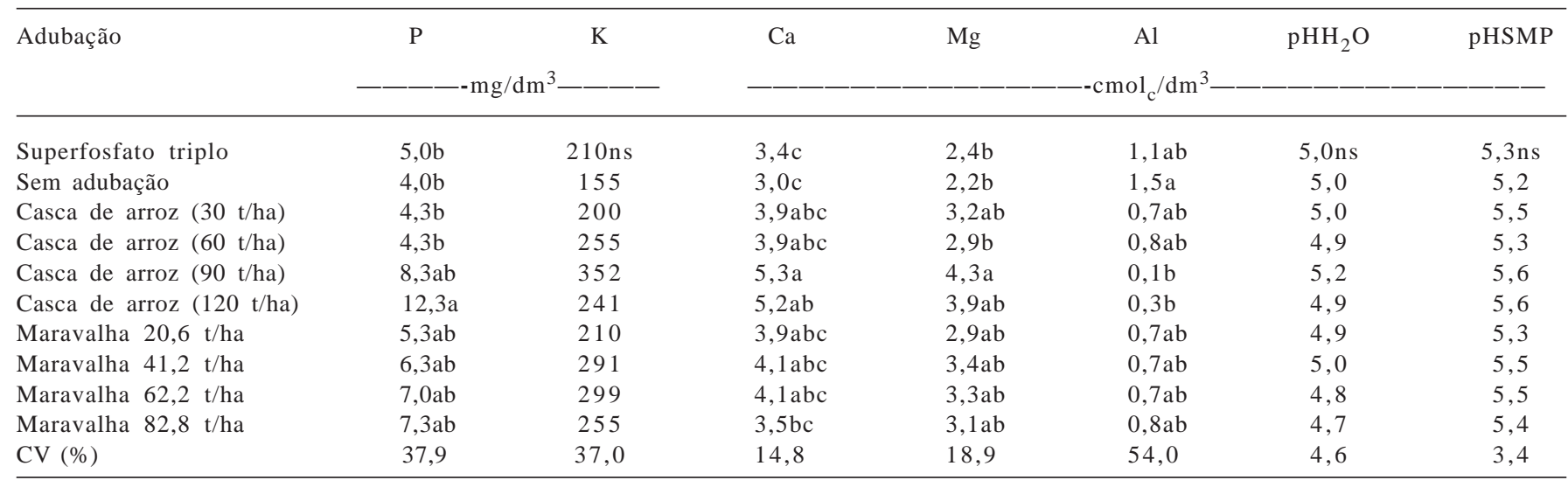

Médias seguidas de mesma letra não diferem $(P>0,05)$ pelo teste Tukey.

Tabela 6 - Média anual do teor de PB, FDA e FDN de uma pastagem natural sobressemeada com leguminosas e adubada com superfosfato triplo ou cama sobreposta de suínos à base de casca de arroz ou de maravalha

\begin{tabular}{llll}
\hline Adubação & PB & FDA & FDN \\
\hline Superfosfato triplo & \multicolumn{1}{c}{ (12,1de } & $41,1 \mathrm{ab}$ & $63,0 \mathrm{a}$ \\
Sem adubação & $10,0 \mathrm{e}$ & $42,8 \mathrm{a}$ & $62,8 \mathrm{a}$ \\
Casca de arroz $(30 \mathrm{t} / \mathrm{ha})$ & $14,2 \mathrm{~cd}$ & $40,7 \mathrm{ab}$ & $61,1 \mathrm{ab}$ \\
Casca de arroz $(60 \mathrm{t} / \mathrm{ha})$ & $15,0 \mathrm{c}$ & $37,8 \mathrm{bcd}$ & $60,0 \mathrm{ab}$ \\
Casca de arroz $(90 \mathrm{t} / \mathrm{ha})$ & $15,7 \mathrm{c}$ & $38,4 \mathrm{bcd}$ & $60,6 \mathrm{ab}$ \\
Casca de arroz $(120 \mathrm{t} / \mathrm{ha})$ & $15,2 \mathrm{c}$ & $40,2 \mathrm{abc}$ & $60,3 \mathrm{ab}$ \\
Maravalha 20,6 t/ha & $14,1 \mathrm{~cd}$ & $39,3 \mathrm{abcd}$ & $58,4 \mathrm{abc}$ \\
Maravalha 41,2 t/ha & $16,1 \mathrm{bc}$ & $38,1 \mathrm{bcd}$ & $54,0 \mathrm{c}$ \\
Maravalha 62,2 t/ha & $18,1 \mathrm{a}$ & $36,0 \mathrm{~cd}$ & $54,0 \mathrm{c}$ \\
Maravalha 82,8 t/ha & $18,4 \mathrm{ab}$ & $35,6 \mathrm{~d}$ & $55,8 \mathrm{bc}$ \\
CV (\%) & 17,8 & 12,4 & 10,8 \\
\hline
\end{tabular}

Médias seguidas de mesma letra não diferem $(P>0,05)$ pelo teste Tukey. 
alteram o crescimento das espécies de uma comunidade vegetal de forma distinta, modificando a composição botânica. Estudos futuros sobre o uso desses adubos devem esclarecer os mecanismos biológicos e fisiológicos associados ao crescimento das espécies (Menalled et al., 2005). Possíveis alterações na dinâmica microbiana do solo, concentrações de elementos químicos que funcionam como reguladores de crescimento e condições físicas do solo relacionadas às cama sobrepostas de suínos devem ser considerados fatores que contribuem, potencialmente, no desempenho das espécies (Liebman et al., 2004).

\section{Conclusões}

A cama sobreposta de suínos é uma alternativa para a adubação de pastagens naturais, pois viabiliza a introdução de leguminosas e aumenta a produção e a qualidade da matéria seca. O tipo de cama sobreposta de suínos influencia na eficiência como fertilizante, interferindo na composição botânica de pastagens mistas de leguminosas-gramíneas. O estabelecimento, a produção e a persistência do trevobranco aumentam com o uso de doses crescentes de cama sobreposta de suínos à base de maravalha. A sobressemeadura do trevo-branco em pastagem natural tem efeito positivo na produção e na qualidade da matéria seca anual, especialmente no período outono-inverno.

\section{Agradecimento}

À Professora MSc. Dileta Cecchetti, pelo auxílio na análise estatística, e à Direção e aos alunos da Escola Agrotécnica Federal de Concórdia, pelo apoio na realização deste trabalho.

\section{Literatura Citada}

ALCARDE, J.C.; GUIDOLIN, J.A; LOPES, A.S. Os adubos e a eficiência das adubações. São Paulo: Associação Nacional para a Difusão de Adubos, 1989. 35p. (Boletim Técnico, 3).

ARNS, A.P. Eficiência fertilizante da cama sobreposta de suíno. Passo Fundo: Universidade de Passo Fundo, 2004. 99p. Dissertação (Mestrado em Produção Vegetal) - Universidade de Passo Fundo, 2004.

BANDINELLI, D.G. Composição florística de pastagem natural afetada por fontes de fósforo, calagem e introdução de espécies forrageiras de estação fria. Ciência Rural, v.35, n.1, p.8491, 2005.

BEINHART, G.; GIBSON, P.B.; HALPIN, J.E. et al. Selection and evaluation of white clover clones. III. Clonal differences in branching in relation to leaf area production and persistence. Crop Science, v.3, p.89-92, 1963.

DOUDS, D.D.; GALVEZ, L.; FRANKE-SYDER, M. et al. Effect of compost addition and crop rotation point upon VAM fungi. Agricultural, Ecosystem \& Environment, v.65, p.257-266, 1997.
FONTANELI, R.S.; JACQUES, A.V.A. Melhoramento de pastagem nativa com introdução de espécies temperadas. Pesquisa Agropecuária Brasileira, v.26, n.10, p.1787-1793, 1991. GATIBONI, L.C.; KAMINSKI, J.; PELLEGRINI, J.B.R. et al. Influência da adubação fosfatada e da introdução de espécies forrageiras de inverno na oferta de forragem de pastagem natural. Pesquisa Agropecuária Brasileira, v.35, n.8, p.1663-1668, 2000.

GURETSKY, J.A.; MOORE, K.J.; KNAPP, A.D. et al. Emergence and survival of legumes seeded into pastures varying in landscape position. Crop Science, v.44, p.227-233, 2004.

HAYSTEAD, A.; MARRIOTT, C. Effects of rates and times of application of starter dressing of nitrogen fertilizer to surface sown perennial ryegrass-white clover on hill peat. Grass and Forage Science, v.34, p.241-247, 1979.

LIEBMAN, M.; MENALLED, F.D.; BUHLER, D.D. Impacts of composted swine manure on weed and corn nutrient uptake, growth, and seed production. Weed Science, v.52, p.365375, 2004.

LIGNEAU, L.A.; WATT, T.A. The effect of domestic compost upon the germination and emergence of barley and six arable weeds. Annals of Applied Biology, v.126, p.153-162, 1995.

LOBATO, J.E.P.; BARRETO, I.L. Comportamento de consorciações de gramíneas temperadas com leguminosas quando implantadas em pastagem natural submetidas a preparo superficial do solo, sob o efeito de quatro doses de calcário e dois métodos de semeadura. Revista da Faculdade de Agronomia e Veterinária da Universidade Federal Rio Grande do Sul, v.1, n.1, p.7196, 1975.

LOW, A.J.; PIPER, F.J. 1960. The influence of water supply on the growth and phosphorus uptake of Italian ryegrass and white clover in pot culture. Plant and Soil, v.13, p.242- 255, 1960.

MACEDO, W.; GONÇALVES, J.O.N.; GIRARDI-DEIRO, A.M. Melhoramento de pastagem natural com fosfatos e introdução de leguminosas em solo da fronteira oeste do Rio Grande do Sul. Revista Brasileira de Ciência do Solo, v.9, p.231-235, 1985.

MAGNANTI, N.J.; ALMEIDA, M.; MAFRA, A.L. Desempenho do fosfato natural alvorada comparado ao superfostato triplo na introdução de pastagem perene de inverno. Revista de Ciências Agroveterinárias, v.4, n.2, p.133-144, 2005.

MENALLED, F.D.; BUHLER, D.B.; LIEBMAN, M. Composted swine manure effects on germination and early growth of crop and weed species under greenhouse conditions. Weed Technology, v.19, p.784-789, 2005.

NATIONAL RESEARCH COUNCIL - NRC. Nutrient requirements of dairy cattle. Washington, D.C: National Academu Press, 1988. 157p.

PRESTES, N.E.; JACQUES, A.V.A. Sobressemeadura do cornichão (Lotus corniculatus L.) cv. São Gabriel em pastagem natural: diferimento e adubação. Revista de Ciências Agroveterinárias, v.2, n.2, p.73-81, 2002.

QUADROS, F.L.F.; MARASCHIN, G.E. Desempenho animal em misturas de espécies forrageiras de estação fria. Pesquisa Agropecuária Brasileira, v.22, p.553-541, 1987.

RESENDE, J.T.V.; SALVADOR, E.D.; FARIA, M.V. et al.. Utilização de resíduos agroindustriais como substrato na produção de mudas de tomateiro. Ambiência, v.1, n.1, p.25-29, 2005.

RitTer, W.; SORRenson, W.J. Produção de bovinos no Planalto de Santa Catarina, Brasil. Eschborn: Deutsche Gesellshaft für Technishe Zusammenarbeit GmBH, 1985. 172p.

RIZO, L.M.; MOOJEN, E.L.; QUADROS, L.F.F. de. et al. Desempenho de pastagem nativa e pastagem sobre-semeada com forrageiras hibernais com e sem glifosato. Ciência Rural, v.34, n.6, p.1921-1926, 2004.

SANTOS, J.C.F.; SOUZA, I.F.; MENDES, A.N.G. et al. Efeito de extratos de cascas de café e de arroz na emergência e no crescimento do caruru-de-mancha. Pesquisa Agropecuária Brasileira, v.37, n.6, p.783-790, 2002. 
SOCIEDADE BRASILEIRA DE CIÊNCIA DO SOLO - SBCS. Manual de adubação e calagem para os Estados do Rio Grande do Sul e de Santa Catarina. Porto Alegre: Comissão de Química e Fertilidade do Solo, 2004. 400p.

SOUZA, D.M.G.; MARTHA JR., G.B.; VILELA, L. Manejo da adubação fosfatada em pastagens. In: PEDREIRA, C.G.S.; MOURA, J.C.; FARIA, V.P. (Eds.). Fertilidade do solo para pastagens produtivas. Piracicaba: Fundação de Estudos Agrários Luiz de Queiroz, 2004. p.101-138.

TAMAK, J. C.; NARWAL, S. S.; SINGH, L. et al. Effect of aqueous extracts of rice stubbles and straw + stubbles on the germination and seedling growth of wheat, oat, beset and lentil. Crop Research, v.8, p.180-185, 1994.

VALDRIGHI, M.M.; PERA, A.; AGNOLUCCI, M. et al. Effects of compost-derived humic acids on vegetable biomass production and microbial growth within a plant (Cichorium intybus) soil system: a comparative study. Agricultural, Ecosystem \& Environment, v.58, p.133-144, 1996.

WHALLEY, R.D.B.; HARDY, M.B. Measuring botanical composition of grasslands. In: 't MANNETJE, L.; JONES, R.M. (Eds.). Field and laboratory methods for grassland and animal production research. Cambridge: CAB International, 2000. p.67-102. 